\title{
Correlation of Musculoskeletal Dysfunctions with Enhanced Computer Usage and Prescription of Management Strategies, In Computer Users of Afro Asian Institute, Lahore (Pakistan)
}

\author{
Dr.Muhammad Tahir Azeem \\ Senior Lecturer and Clinical Therapist, Afro Asian Institute, Lahore, (Pakistan) \\ Engr.Imran Siddique ${ }^{\bar{\top}}$ \\ Senior Lecturer Computer Science Department, Afro Asian Institute, Lahore \\ Dr.Faseeh Zulqernain \\ Senior Lecturer, Sargodha Institute of Health Sciences, Sargodha (Pakistan) \\ Dr.Tehmina Irfan \\ Consultant Physiotherapist Iqra Medical Complex, Lahore (Pakistan) \\ Muhammad Zubair Awan \\ Senior Lecturer Computer Science Department, Afro Asian Institute, Lahore
}

\begin{abstract}
OBJECTIVE: To nail down the frequency of musculoskeletal problem's in computer users and Recommend treatment/management options to the papulation with MSK problems.

STUDY DESIGN: It is a cross-sectional descriptive study.

PLACE AND DURATION: This study was performed from April 2019 to November 2019 at Afro Asian institute. Lahore (Pakistan).

METHODOLOGY: One hundred subjects (54 males and 46 females) who were using computers were studied from Afro Asian institute Lahore. We used a questionnaire for collecting data about MSK status of individuals, data was statistically analyzed using SPSS. We used Chi-square test for evaluation of data. Moreover, Physiotherapy Management (Postural education, stretching of tightened structures, strengthening of weakened structures, heating modalities and periodic AROM exercises) and medical management (NSAIDS, muscle relaxant, analgesics) was prescribed for improvements, according to the severity and grading of MSK problems.

RESULTS: The frequency of MSK dysfunctions was $52.60 \%$ in those who had been using computers for less than or equal to $2 \mathrm{hrs}, 68.15 \%$ for $2-4 \mathrm{hrs}$ computer users, $81.45 \%$ for subjects with computer using of $4-6 \mathrm{hrs}$, and $93.72 \%$ in subjects who were using computer for more than 6 hours, respectively. The frequency of MSK problems (cervicalgia, LBP, shoulder pain, and elbow pain and pain in carpels) was classified according to a scale of pain ranging from grade $\mathrm{I}$ to grade $\mathrm{V}$.
\end{abstract}

Keywords: Musculoskeletal Problems, Management Strategies, Postural Education

DOI: $10.7176 / \mathrm{JHMN} / 71-08$

Publication date: February $29^{\text {th }} 2020$

\section{Introduction}

Computer usage has increased promptly from the invention of microcomputer-systems in the early years of $1970 \mathrm{~s}$, becoming almost apparent in affluent countries.' $64 \%$ of adults in the U.S.were using a computer in year 2003, and computer use by younger age group people are even more prevalent. $99 \%$ of Australian children between the ages of 11 - 14 used a computer in years $2003 \& 2004$. This recent surge in computer use has caused concern that greater the time spent in front of a computer, greater may be adverse effect on the health and development of adolescents. Computer usage may affect physical health indirectly by displacing more vigorous physical activities.' Evidence in support of this displacement has an inverse association between vigorous physical activity and computer use in young children, although some other researches have proved positive associations between physical activity and computer usage in adolescents. According to a recent research of computer operators working intensively with small pointing tools, about $10.7 \%$ computer users complained about moderate to severe pain in the neck religion and $7.7 \%$ in the right shoulder during the previous week. The incidence of pain has increased with enhanced computer work: However, away from a possible link to stress in the neck, the physical examination in workers with symptoms was unable to show clinical somatic disorders responsible for the prevalent and severe complaints. The literature review on musculoskeletal disorders includes ongoing discussions which concern both the relevance of the measured outcomes along with the deficiency of Longitudinal Studies. One group that is interested in computer users, among whom several factors have been identified as being associated with 
musculoskeletal disorders: physical and ergonomic factors, work organization, psychosocial factors, working technique, hours spent on computer, and gender: Studies among more general groups have indicated that workrelated physical factors (heavy load, awkward positions, repetitive movements) and psychosocial factors i.e. demands, control and mental stress, as well as multiple individual risk factors (age, gender, weight, substance abuse, activity level), re very important in the understanding of neck and shoulder pain. Activity limitation and long-term disability is caused mostly by MSK disorders raising health budget. Over the last few years, the proportion of the working population with primarily sedentary office work with low-load repetitive movements has increased. In the same period, increase in the prevalence of neck-shoulder pain has raised.' Correspondingly, computer industry is one of the highest risk for neck-shoulder pain causing occupation,' and extended computer work is considered a trigger for neck-shoulder pain, often present in the upper part of the pectoral girdle. The high prevalence of neck-shoulder pain in computer users is generally considered to be mediated by insufficient upper trapezius rest, causing increased load and disturbance in local circulation. Work-related neck disorders (WRNDs) is very common problem in computer workers, particularly in those who are frequent computer users. The present study was undertaken to give documentary proof on the basis of completely filled questionnaires to overcome the difficulties in obtaining information verbally from computer users.

\section{Methodology}

This descriptive study was conducted in 2019 at Afro Asian Institute. A questionnaire was designed and distributed among 100 computer users. In this descriptive, cross-sectional study, data were statistically evaluated using the Chi-square test. A $p$ value $<0.05$ was considered significant. The questionnaire was comprised of questions inquiring about the musculoskeletal complications (neck pain, low backache, shoulder pain, pain at the elbow joint, and pain at the wrist) in computer users. These complications were measured and treated according to the scale for grading the severity of pain which ranged from grade I to grade V31 (Table 1). The students were grouped according to the numbers of hours they spent working on the computer i.e. $(<2 \mathrm{hrs}, 2-4 \mathrm{hrs}$, 4-6 hrs, and $>6$ $\mathrm{hrs}$ ). With respect to the grade of pain recorded, remedies (rest, physiotherapy, and no steroidal anti-inflammatory drugs (NSAIDs) and muscle relaxants) were provided for the relief from the complications31 (Table VI).

\section{Results}

In this study 100 computer users were selected from Afro Asian Institute. This sample was comprised of 54\% and $46 \%$ male and female students, respectively. Their ages ranged from 18 to 30 years. The frequency of musculoskeletal complications in computer users was observed with respect to the number of hours $(<2 \mathrm{hrs}, 2-4$ hrs, 4-6 hrs, $>6 \mathrm{hrs}$ ) that the group maintained in consistent daily contact with computers. The frequency of musculoskeletal complications was determined to be $77 \%$ of students; the remainder $(23 \%)$ were deemed healthy. The $19 \%$ of computer users working with computer for $<2$ hours showed musculoskeletal complications in males $(6,31.57 \%)$ and females $(4,21.05 \%)$ with $\mathrm{p}<0.05$, respectively (Table II). Of the group who maintained computer contact for 2 to 4 hours, 7 (31.81\%) males and 8 (36.36\%) females developed musculoskeletal complications ( $\mathrm{p}<$ $0.05)$. In the group of subjects who used computers from 4 to $6 \mathrm{hrs}$ per day, $37.03 \%$ of the males and $44.44 \%$ of the females showed musculoskeletal complications $(p<0.05)$. The highly significant ratio $(p<0.01)$ of musculoskeletal complications (males, 18, 56.25\%) and (females, 12, 37.5\%) was observed in subjects who had used the computer for more than 6 hours (Table III). The frequency of the neck pain was directly associated with increasing working hours spent on the computer (Table IV). With respect to low backache, there was no significant change in its frequency when subjects were in contact with the computer for $<2 \mathrm{hr}$. or from 2 to $4 \mathrm{hr}$. However, the frequency of low backache increased with increasing $(\mathrm{p}<0.01)$ contact hours i.e. 4-6 hrs and more than 6 hours (Table IV). A smaller percentage $(2.59 \% ; 2$ subjects) for shoulder pain was seen in those working $<2 \mathrm{hr}$, but it gradually increased with the increase in contact hours $(7.79 \% ; 6$ subjects). However, those working on the computer for 2-4 and 4-6 hr. showed the same result (5.19\%; 4 subjects). Elbow and wrist pain was not observed at all in subjects using the computer for less than 2 hours but its frequency gradually increased with the number of hours and highest value $(\mathrm{p}<0.01)$ was $4(5.19 \%)$. Neck pain of grade 1 occurred in 5 subjects $(6.49 \%)$ working for less than 2 hours; low backache and shoulder pain of grade II was seen in $3(3.89 \%)$ and $2(2.59 \%)$ subjects, respectively, in that time group. Those using the computer between 2-4 hr. had neck pain of grade II (7 subjects, $9.09 \%$ ), low backache of grade I in 3 subjects (3.89\%), and elbow/wrist pain of grade II) in 1 subject (1.29\%). However, shoulder pain of grade III in this time group occurred in 4 subjects $(5.19 \%)$.In the group working for $4-$ $6 \mathrm{hr}$. on the computer, neck pain of grade III occurred in 11 subjects (14.28\%), shoulder pain of grade III in 4 $(5.19 \%)$, and elbow/wrist pain of grade III was seen in $2(2.59 \%)$. Low backache of grade IV, however, was noted in 5 subjects $(6.49 \%)$. In those subjects working more than $6 \mathrm{hr}$, neck pain, shoulder pain, and elbow/wrist pain were grade IV, while low backache was grade V (Table V). The computer users who had the musculoskeletal complications of grade I to III were advised to rest, perform physiotherapy, and take NSAIDs. Those with pain of grades IV to $\mathrm{V}$ were advised for rest, perform physiotherapy, and take NSAIDs and also muscle relaxants. Improvement was noticed in musculoskeletal complications in those with grade I to III and grade IV to V, 
respectively.

\section{Discussion}

Our study showed that $77 \%$ of computer workers developed complications in muscular and skeletal system from computer using of 2 hours to 6 or more hours. In addition, recent longitudinal studies suggest a relationship between the duration of mouse use and the incidence of hand-arm symptoms. Blangsted observed muscular fatigue as measured with mechanomyography and electromyography in the extensor carpi radialis muscle $30 \mathrm{~min}$ following a $10 \mathrm{~min} 10 \% \mathrm{MVC}$ wrist extension. 33 In our study, the frequency of neck pain increased in computer users with the number of hours they maintained contact with the computer. Other studies have reported that musculoskeletal tissue injuries associated with work-place risk factors are known by a wide variety of terms, including cumulative trauma disorders, repetitive strain injuries, 34 and overuse injuries. 35 for those people who are spending a much time using computers, work-related musculoskeletal disorders (WRMSDs) of the neck and shoulder are a common problem.36work-related neck pain's incidence (WRNP) in computer users ranges from $23.5 \%$ for a six-month incidence 37 to an annual incidence of $34.4 \%$ (95\% CI 25.541.3). The prevalence of neck pain in our study rose significantly with computer use ranging from $2 \mathrm{hr}$. to hr. The highest prevalence rates were found for neck and shoulder symptoms (33\% and 31\%, respectively), followed by hand and upper arm complaints (11\% to $12 \%)$, and elbow, lower arm, and wrist complaints $(6 \%$ to $7 \%) .39$ Boet et al. found in a Dutch cohort of general practice patients incidence rates of 23.1 cases per 1,000 person-years for MSK problems in neck., followed by 19.0 cases per 1,000 for MSK problems in shoulder. $4^{\circ}$ Furthermore, a study in Netherlands concluded that in the year 2002 and year 2004, $28 \%$ of the working people reported symptoms in neck/shoulder or elbow/ wrist/hand in the last 12 months' and that these symptoms were hypothetically caused by work. Another study in the USA' indicated that among their 416 employees, $63 \%$ reported neck and shoulder symptoms compared to $34 \%$ who reported symptoms in arm or hand.In view of the results of different studies on musculoskeletal complications due excessive computer use, our study also confirmed that there is a strong relationship between the development of different types of musculoskeletal complications and increased numbers of working hours with a computer. Furthermore, remedies (pharmacological and non-pharmacological) provided offer new opportunities to give relief from these symptoms.

\section{Conclusion}

This study revealed that in most of the subjects MSK problems increased in direct proportion with the increasing time of computer using. Information from data evaluation helped us to suggest management plans according to severity and grading of problems.

TABLE I: CRITERIA FOR GRADING OF PAIN

\begin{tabular}{|c|c|c|c|c|}
\hline \multirow{3}{*}{ Complications } & \multicolumn{5}{|c|}{ Working Hours } \\
\cline { 2 - 5 } & $<02$ Hrs & $>02-04$ Hrs & $>04-06$ Hrs & $>06$ Hrs \\
\cline { 2 - 5 } & $\mathbf{N}=19(\%)$ & $\mathbf{N}=22(\%)$ & $\mathbf{N}=27(\%)$ & $\mathbf{N}=32(\%)$ \\
\hline Musculo Skeletal & $\mathbf{1 0 ( 5 2 . 6 0 ) *}$ & $15(68.15)^{*}$ & $22(81.45)^{*}$ & $30(93.72)^{* * *}$ \\
\hline Healthy & $9(47.36)$ & $7(31.81)$ & $5(18.51)$ & $2(6.25)$ \\
\hline
\end{tabular}

TABLE - II: THE FREQUENCY OFMUSCULOSKELETAL COMPLICATIONS

\begin{tabular}{|c|c|}
\hline GRADE & DESCRIPTION \\
\hline I & Pain during activity for a short period \\
\hline II & Pain that persists for a longer period after activity \\
\hline III & $\begin{array}{c}\text { Pain that progresses during activity that require practice session to be shorten but resolves } \\
\text { between sessions }\end{array}$ \\
\hline IV & Pain that progresses during activity that does not totally resolve between sessions \\
\hline V & Continuous pain preventing from activity and persists even at rest and at night \\
\hline
\end{tabular}

TABLE III THE FREQUENCY OF MUSCULOSKELETAL COMPLICATIONS IN MALE AND FEMALE STUDENTS

\begin{tabular}{|c|c|c|c|c|c|c|c|c|}
\hline Working hours & \multicolumn{2}{|c|}{$<02 \mathrm{hrs}$} & \multicolumn{2}{c|}{$>02-04 \mathrm{hrs}$} & \multicolumn{2}{c|}{$>04-06$} & \multicolumn{2}{c|}{$>06 \mathrm{hrs}$} \\
\hline No. of students & \multicolumn{2}{|c|}{$\mathrm{n}=19(\%)$} & \multicolumn{2}{c|}{$\mathrm{n}=\mathbf{2 2}(\%)$} & \multicolumn{2}{c|}{$\mathrm{n}=27(\%)$} & \multicolumn{2}{c|}{$\mathrm{n}=32(\%)$} \\
\hline Complications & Male & Female & Male & Female & Male & Female & Male & Female \\
\hline $\begin{array}{c}\text { Musculo } \\
\text { skeletal }\end{array}$ & $\mathbf{6 ( 3 1 . 5 7 )}$ & $\mathbf{4 ( 2 1 . 0 5 )}$ & $\mathbf{7 ( 3 1 . 8 1 )}$ & $\mathbf{8 ( 3 6 . 3 6 )}$ & $\mathbf{1 0 ( 3 7 . 0 3 )}$ & $\mathbf{1 2 ( 4 4 . 4 4 )}$ & $\mathbf{1 8 ( 5 6 . 2 5 )}$ & $\mathbf{1 2 ( 3 7 . 5 )}$ \\
\hline Healthy & $\mathbf{5 ( 2 6 . 3 1 )}$ & $\mathbf{4 ( 2 1 . 0 5 )}$ & $\mathbf{4 ( 1 8 . 1 8 )}$ & $\mathbf{3 ( 1 3 . 6 3 )}$ & $\mathbf{3 ( 1 1 . 1 1 )}$ & $\mathbf{2 ( 7 . 4 0 )}$ & $\mathbf{1 ( 3 . 1 2 )}$ & $\mathbf{1 ( 3 . 1 2 5 )}$ \\
\hline
\end{tabular}


TABLE - IV: THE FREQUENCY OF MUSCULOSKELETAL COMPLICATIONS

\begin{tabular}{|c|c|c|c|c|}
\hline \multirow{2}{*}{ WORKING HRS } & \multicolumn{4}{|c|}{ MUSKULOSKELETAL COMPLICATIONS } \\
\cline { 2 - 5 } & Neck pain (\%) & Low backache (\%) & Shoulder pain (\%) & Elbow and wrist pain (\%) \\
\hline$<2 \mathrm{hrs}$ & $6.49^{*}$ & $3.89^{*}$ & $2.59^{*}$ & 0 \\
\hline $02-04 \mathrm{hrs}$ & $9.09^{*}$ & $3.89^{*}$ & $5.19^{*}$ & $1.29^{*}$ \\
\hline $05-06 \mathrm{hrs}$ & $14.28^{*}$ & $6.49^{*}$ & $5.19^{*}$ & $2.59^{*}$ \\
\hline$>06 \mathrm{hrs}$ & $16.88^{*}$ & $9.09^{*}$ & $7.79^{*}$ & $5.19^{*}$ \\
\hline
\end{tabular}

TABLE - V: THE FREQUENCY OF MUSCULOSKELETAL COMPLICATIONS BASED ON GRADING OF PAIN

\begin{tabular}{|c|c|c|}
\hline $\begin{array}{c}\text { GRADING OF } \\
\text { COMPLICATIONS }\end{array}$ & REMEDIES TAKEN & OUTCOME \\
\hline I & Rest, physiotherapy, NSAIDs & \multirow{3}{*}{$\begin{array}{l}\text { Improvement was noticed on } \\
\text { follow-up }\end{array}$} \\
\hline II & Rest, physiotherapy, NSAIDs & \\
\hline III & Rest, physiotherapy, NSAIDs & \\
\hline IV & $\begin{array}{l}\text { Rest, physiotherapy, NSAIDs and muscle } \\
\text { relaxant }\end{array}$ & $\begin{array}{l}\text { Improvement was noticed on } \\
\text { follow-up }\end{array}$ \\
\hline $\mathbf{V}$ & $\begin{array}{c}\text { Rest, physiotherapy, NSAIDs and muscle } \\
\text { relaxant }\end{array}$ & $\begin{array}{l}\text { Improvement was noticed on } \\
\text { follow-up }\end{array}$ \\
\hline
\end{tabular}

TABLE VI: RESULTS OF REMEDIES GRADING OF COMPLICATIONS

\begin{tabular}{|c|c|c|c|c|}
\hline $\begin{array}{c}\text { MUSCULO- } \\
\text { SKELETAL } \\
\text { COMPLICATION }\end{array}$ & \multicolumn{4}{|c|}{ WORKING HOURS } \\
\cline { 2 - 5 } & $<02 \mathrm{hrs}$ & $>02-04 \mathrm{hrs}$ & $>04-06 \mathrm{hrs}$ & $>06 \mathrm{hrs}$ \\
\hline Neck pain & Grade I* & Grade II* & Grade III* & Grade IV** \\
\hline Low backache & Grade II* & Grade II* & Grade IV* & Grade V** \\
\hline Shoulder pain & Grade II* & Grade III* & Grade III* & Grade IV** \\
\hline Elbow + wrist joint & 0 & Grade II* & Grade III* & Grade IV** \\
\hline
\end{tabular}

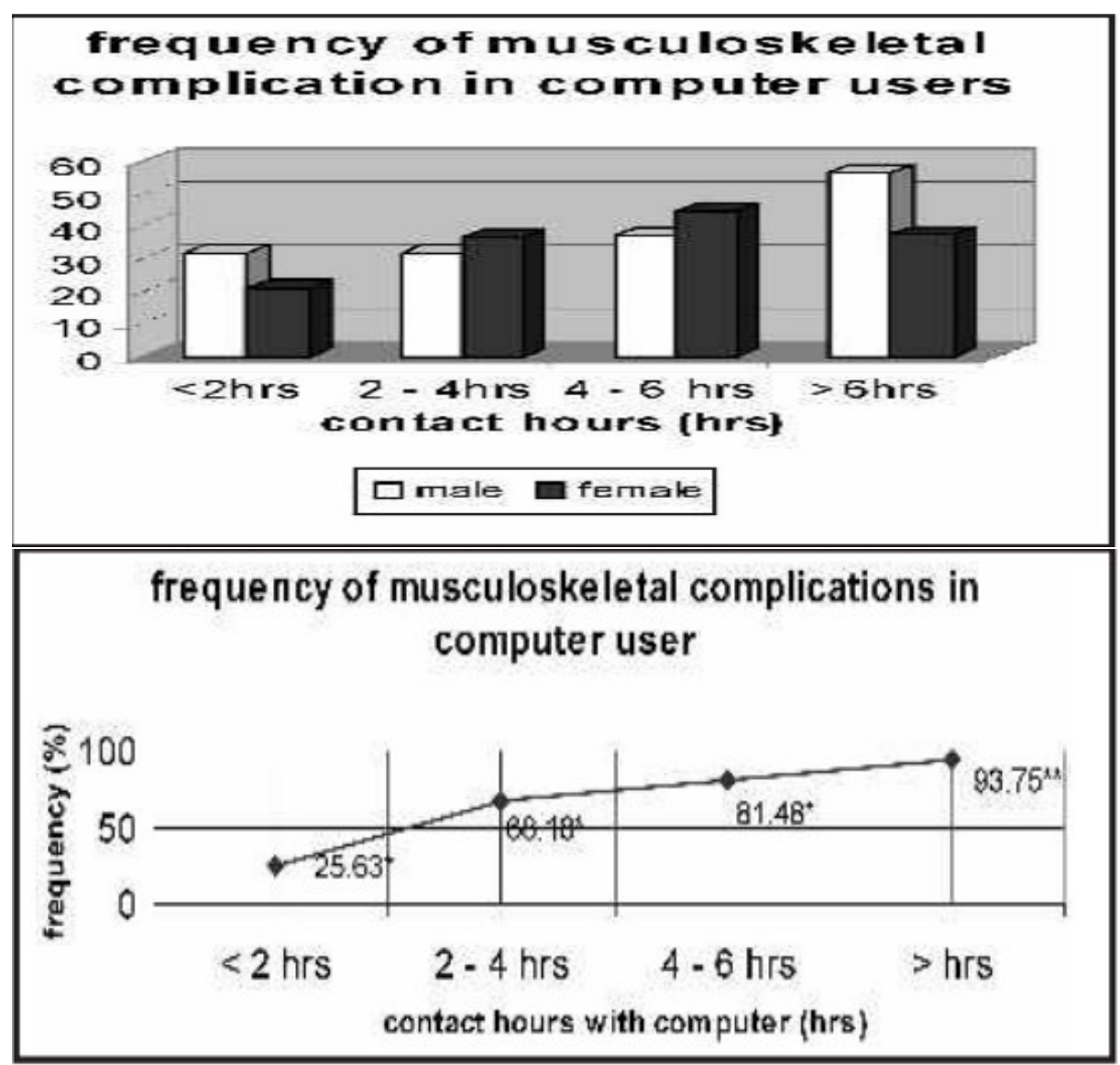




\section{Acknowledgment}

The author is thankful to Afro Asian Institute, Lahore (Pakistan) for providing a platform to perform this study and their cooperation for maintain a good researching environment for data collection of research.

\section{References}

1. Day, J. C., Janus, A., \& Davis, J. (2005). Computer and Internet use in the United States, 2003. US Department of Commerce, Economics and Statistics Administration, US CENSUS BUREAU.

2. Subrahmanyam, K., Greenfield, P., Kraut, R., \& Gross, E. (2001). The impact of computer use on children's and adolescents' development. Journal of Applied Developmental Psychology, 22(1), 7-30.

3. Demunter C. Luxembourg: Statistical Office of the European Communities; 2005. The digital divide in Europe. Publication no. 38/2005

4. Australian Bureau of Statistics. Canberra (New South Wales): Australian Bureau of Statistics; 2003. Children's participation in cultural and leisure activities, Australia. Publication no. 4901.

5. Straker L, Pollock C, Burgess Limerick R. Towards evidence based guidelines for wise use of computers by children. Int J Ind Ergon 2006;36:104553

6. Greig A, Straker L, Briggs A. Cervical erector spinae and upper trapezius muscle activity in children using different information technologies. Physiotherapy 2005;91:11926

7. Straker $\mathbf{L}$, Briggs A, Greig A. The effect of individually adjusted workstations on upper quadrant posture and muscle activity in school children. Work 2002;18:23948

8. Straker LM, Pollock CM, Zubrick SR, Kurinczuk JJ. The association between information and communication technology exposure and physical activity, musculoskeletal and visual symptoms and socioeconomic status in 5-year-olds. Child Care Health Dev 2006;32:34351

9. Ho SM, Lee TM. Computer usage and its relationship with adolescent lifestyle in Hong Kong. J Adolesc Health $2001 ; 29: 25866$

10. Lassen CF, Mikkelsen S, Kryger Al, Brandt LP, Overgaard E, Thomsen JF, Vilstrup I, Andersen JH. Elbow and wrist/hand symptoms among 6,943 computer operators: A 1-year follow-up study (The NUDATA study). Am J Ind Med 2004;46:52133

11. Andersen JH, Haahr JP, Frost P. Risk factors for more severe regional musculoskeletal symptoms: a twoyear prospective study of a general working population. Arthritis Rheum 2007;56:135564

12. Andersen JH, Kaergaard A, Mikkelsen S, Jensen UF, Frost P, Bonde JP, Fallentin N,Thomsen JF. Risk factors in the onset of neck/shoulder pain in a prospective study of workers in industrial and service companies.Occup Environ Med 2003; 60:64954

13. Ariens GA, van Mechelen W, Bongers PM, Bouter LM, van der Wal G. Psychosocial risk factors for neck pain: a systematic review. Am J Ind Med 2001;39:18093

14. Huisstede BM, Bierma-Zeinstra SM, Koes BW, Verhaar JA. Incidence and prevalence of upper extremity musculoskeletal disorders. A systematic appraisal of the literature.BMC Musculoskelet Disord 2006;7:7

15. Gerr F, Monteilh CP, Marcus M. Keyboard use and musculoskeletal outcomes among computer users. J Occup Rehabil 2006;16:26577

16. Wahlstrom J. Ergonomics, musculoskeletal disorders and computer work. Occup Med(Lond) 2005;55:16876

17. Karels CH, Bierma-Zeinstra SM, Burdorf A, Verhagen AP, Nauta AP, Koes BW. Social and psychological factors influenced the course of arm, neck and shoulder complaints. J Clin Epidemiol 2007;60:83948

18. Ryall C, Coggon D, Peveler R, Reading I, Palmer KT. A case-control study of risk factorsfor arm pain presenting to primary care services. Occup Med 2006;56:13743

19. Walker-Bone K, Reading I, Coggon D, Cooper C, Palmer KT. Risk factors for specific upper limb disorders as compared with non-specific upper limb pain: assessing the utility of a structured examination schedule.

20. Santos MP, Gomes H, Mota J. Physical activity and sedentary behaviors in adolescents.Ann Behav Med 2005;30:214 2006;56:24350

21. Badley EM, Webster GK, Rasooly I. The impact of musculoskeletal disorders in the population: are they just aches and pains? Findings from the 1990 Ontario Health Survey. J Rheumatol 1995;22:7339 